\title{
Supporting Self-Directed Learning: A Framework for Teachers
}

\author{
Katherine Thornton \\ Kanda University of International Studies, Japan \\ katherine-t@kanda.kuis.ac.jp
}

\begin{abstract}
The language learning process is a complicated one, and although classroom study forms the backbone of this process for many learners, motivated students will also engage in their own language study independent of the teacher. This paper examines four aspects of the learning process that self-directed learners are generally understood to be able to navigate: planning, implementing, monitoring, and evaluating; it then suggests ways in which teachers can foster these abilities in the language learning classroom. By teaching specific strategies for different learning tasks, encouraging reflection and self-analysis, and raising learners' awareness of their own learning processes in addition to features of the language they are studying, teachers can help learners to assume more responsibility for their own learning, and thus to become more effective language learners.
\end{abstract}

In order to be successful, most language learners will have to engage in independent study to some degree to master a language; the growth of self-access centres in institutions around the world is a reflection of the importance of this process. Institutions and managers have realised that learners can only reach their full potential when they have the flexibility to study according to their own needs, learning styles, and interests, and that classroom-based learning scenarios are only a small part of the overall process of learning a foreign language. Of those learners serious about mastering a language, even those who do not have access to a state-ofthe-art resource centre will likely be engaging in their own self-directed study, independent of their class work or homework set by the teacher. This willingness to seek out their own learning opportunities and engage with the language on their own terms is a common theme seen in studies of identified "Good Language Learners" (Griffiths, 2008). Such good language learners often develop very effective strategies which help them make considerable progress in their language learning; however, for every successful, motivated, independent learner, there are many others who, despite their efforts, struggle to make meaningful progress or experience problems with self-motivation and lack of confidence in their study strategies.

In these circumstances, the role of the teacher is vital. By providing support and guidance for learners, teachers can help their students develop the skills to be successful self-directed learners with clear goals, appropriate resources, and effective learning strategies. This paper aims to provide a framework to help teachers support their learners in developing autonomous learning skills which can enhance their language learning both inside and outside the classroom. It draws on the experience of the author, a Learning Advisor in a Self-Access Learning Centre in Japan, in encouraging learners to analyse their own situations and develop the skills to be able to take full control of their own learning process. While a self-access centre in which learners are aware of the need to make their own decisions about their learning may

Language Education in Asia, 2010, 1(1), 158-170. http://dx.doi.org/10.5746/LEiA/10/V1/A14/Thornton 
be an ideal environment for learners to engage in such analysis, classroom teachers can also foster independent learning skills in their students in a similar fashion by incorporating simple activities into their lessons and encouraging self-analysis during classroom tasks.

\section{Literature Review}

Self-directed learning: An overview. The concept of self-directed learning first came to prominence within the field of adult education in the 1970s and is closely associated with learner autonomy, an area of research which has received increasing attention over the last two decades. It is now generally accepted that autonomous learners, that is, learners who are willing to assume more control over the learning process, will be more engaged, and that the decisions the learners make about learning will lead to more focused and effective study. References to learner autonomy can now be found in most published textbooks, and it is a stated aim on many language courses around the world, regardless of teaching and learning contexts. Existing definitions of autonomy are, however, often vague, and of limited usefulness for classroom teachers wanting to foster or even assess this aspect of their learners' development. According to Holec, an autonomous learner has the "the ability to take charge of one's learning" (1981, p. 3), but it is unclear as to exactly what "take charge" should mean, especially in many classroom contexts in which much of the control over learning content and activities are in the hands of the teacher. To complicate matters further, Nunan (1997) highlights that autonomy is not a characteristic or even a permanent state, that learners may be more or less autonomous at different times and as regards different areas of their learning, and that learner variables such as personality, cultural context, and prior educational experiences will affect the degree to which learners may be willing or able to become more autonomous in learning. This presents a further challenge to teachers wishing to help learners develop these skills in a classroom environment.

Dickinson (1987) offers clear definitions of a number of terms surrounding autonomy which many other researchers and practitioners have a tendency to use interchangeably. Under the banner of self-instruction, "when a learner, with others, or alone, is working without the direct control of a teacher" (1987, p. 9), Dickinson distinguishes between self-directed and autonomous learning, with self-direction being one step on the path to full autonomy as a learner. He defines self-directed learning as a state in which the learner is fully in control of the decision-making process regarding the learner's own learning and accepts full responsibility for it, but "will probably seek expert help and advice" $(1987$, p. 12). This may mean that the learner chooses to study in a teacher-led environment or chooses to undertake and manage all learning tasks independently, in which case the learner would be regarded as fully autonomous, or any variation of these two extreme positions. For the purposes of this paper, the term self-directed learning is preferred over autonomous learning to emphasise the validity of a student choosing to undertake more traditional classroom study and to recognize the importance of the role of the teacher to many learners who are just beginning to take control of their own learning. Students who realize their own limits in certain situations and choose to seek guidance from teachers are nonetheless being self-directed; this decision-making process should be acknowledged and respected, despite being neglected by most definitions of learner autonomy.

Self-directed learning is also often closely associated with the field of self-access learning, although Dickinson (1987) points out an important distinction between the two terms. Selfaccess learning is a description of the way in which resources are organized and may be selfor other-directed, although many learners choosing to use self-access resources are likely to have assumed at least a degree of control over the decisions made regarding their learning. Self-directed learning is, however, equally possible without the provision of self-access centres 
or a great mass of learning resources. Accounts of good language learners (Rubin \& Thompson, 1994; Griffiths, 2008) provide numerous examples of self-directed learning behaviour from learners with few physical resources available to them.

The role of the teacher in self-directed learning. One persistent myth about self-directed learning is that it necessarily involves the teacher becoming redundant. This could not be further from the truth, with various studies highlighting the different, but equally important roles teachers or other professionals can play in helping students develop the skills to become more self-directed in their learning (Little, 1991; Dam, 1995; Karlsson, Kjisik, \& Nordlund, 2007). The main tenet of this paper is that the teacher has a vital role to play in this process, and that considerable steps towards greater learner autonomy in self-directed learning can be made through simple adaptations to classroom activities or the inclusion of short discussions and reflections.

Literature on preparing learners for more independent learning emphasises that to become truly self-directed, a number of different kinds of preparation are needed: methodological, psychological, and social/political. Holec's oft-cited definition of autonomy refers mainly to methodological decisions that learners must be able to make (1981, p. 3), such as determining objectives, selecting resources, monitoring the learning process, and evaluating what has been learned. Little's (1991) definition pays added attention to the cognitive or psychological aspects of preparation that learners require, such as the capacity for critical reflection. Benson (2001) adds to these elements the need for learners to have control over learning content, including not only what to learn, but also how they learn, thus introducing a social and political element that educators hoping to foster autonomy must also address.

These three kinds of preparation for self-directed learning may seem to place a heavy burden on already busy teachers, but Dickinson (1992) highlights ways in which these aspects can be incorporated into the classroom without significant disruption. He identifies six different roles for teachers in developing learners' independence. As part of the psychological training, teachers must legitimize independent learning by showing that they approve of more selfdirected learning behavior. Teachers must also help learners adjust to new roles for both learners and teachers by convincing learners that they are capable of successfully making their own learning decisions. On a methodological level, teachers must also provide opportunities for increased independence in the classroom through introducing elements of student choice into the curriculum and language tasks, developing learners' language awareness, and sharing their own knowledge of language learning to help learners solve learning problems effectively. Teachers can also help learners develop learning strategies through awareness raising, explicit instruction, and provision of opportunities for strategy use (1992, p. 2-3). By incorporating this degree of choice into the curriculum, Benson's (2001) social and political aspect of the process can also be addressed.

One of the main roles of the teacher in developing greater independence in learners is often seen as that of learning strategy instructor (Oxford, 1990; O'Malley \& Chamot, 1990). The field of language learning strategies has gained much attention in recent years. Various attempts have been made to describe and categorise different learning strategies (Oxford, 1990; Chamot, Barnhardt, Beard El-Dinary, \& Robbins 1999), or organize them into hierarchies (McDonough, 1999), but no consensus has yet been widely agreed on. By introducing strategy instruction and integrating it with language instruction, teachers can help to develop their learners' capacity to be self-directed. Chamot et al. (1999) propose a model of language learning that requires four metacognitive processes: planning, monitoring, problem-solving, and evaluating; they assign their strategies to one or more of these areas, suggesting ways in 
which the strategies can be taught in a classroom context. Chamot et al. (1999) emphasise the need for learners to have opportunities to try out strategies and to realize that they work, characterizing this as the most effective kind of instruction, a view also espoused by Dickinson (1992).

The literature clearly shows that to be successful, learners need some kind of training or preparation as they embark on self-directed learning, and that teachers are ideally placed to help learners develop the necessary skills. While practical or methodological concerns such as learning strategies are extremely important, without cognitive or psychological preparation such as that described by Little (1991) and Dickinson (1992), attempts to prepare students to take more control over their learning process may meet with less than complete success; any teacher looking to encourage effective self-directed learning should bear this in mind.

\section{Self-Directed Learning in Practice: Four Phases}

As the review of the literature has shown, there are a number of key skills which learners are able to employ if they successfully assume full control of the learning process. This section of the paper addresses these methodological aspects of self-directed learning, offering concrete ideas for teachers wishing to help their students develop these skills. To lend a degree of structure to the introduction of activities to help learners acquire these skills, four phases of a self-directed learning cycle were identified and are used as a basic framework. These have been developed and adapted from Holec's (1981) account of autonomy and Chamot et al.'s (1999) strategy inventory: planning, implementing, monitoring, and evaluating.

The central idea of reflection runs through all these phases. With less direct intervention from teachers to tell them where they may be going wrong, learners must make their own decisions based on critical reflection of their own situation. This requires a certain insight into the learning process, which a teacher can help them to develop. As the term cycle suggests, these four phases are in fact recursive, and learners fully aware of their learning process are unlikely to proceed through the steps in a linear manner without re-addressing some areas at some time. Nevertheless, such a framework is useful to bring some structure to the introduction of each phase and corresponding activities. By developing these skills, it is hoped that learners who choose to engage in study outside of the classroom will be more focused and thus more successful in their endeavours.

\section{Planning}

Analyzing needs. Any account of self-directed learning will inevitably highlight the need for learners to plan what and how they are going to learn. Traditionally, this will start with a needs analysis. Needs analyses first became popular in the area of curriculum design (Munby, 1978), and it is now common practice for teachers or institutions to conduct a needs analysis with a class before finalizing the syllabus. In self-directed learning, the onus is on learners to analyze their own situation and decide on learning priorities. In the author's experience, this involves more than just looking at specific present or future needs for the language. Learners have to take into account their wants and interests. For self-directed learning to be successful, learners must be engaged and motivated. Where language wants and needs do not converge, learners who feel they must study strictly according to extrinsic needs when their real interests lie elsewhere may find their motivation for independent study lacking. By broadening the concept of a needs analysis to include wants and interests, learners can become aware of potential mismatches in their choices and be better placed to deal with them if they arise.

Appendix $A$ is an example of a needs analysis questionnaire to be used with learners who are preparing for learning outside the classroom. Although a needs analysis traditionally takes the 
form of a questionnaire, this is not the only option available to teachers and learners. Equally useful may be a group discussion using similar questions to the questionnaire as prompts, although to get the full benefit from the discussion, learners should be encouraged to make a written record of what they talked about.

Analyzing current skills. Once learners have determined which areas of language they want or need to focus on, the next step is to determine their current skill level. A learner who needs to be able to deliver a formal presentation in English and thinks he needs to work on his pronunciation may in fact have no significant problems in this area. Instead, he may be lacking the academic vocabulary necessary to transition between sections of his talk. By determining his current level in the skills identified in the needs analysis, the learner can then choose specific areas of language on which to focus. This may be done by seeking teacher or peer feedback on written or spoken performance, or by completing a comprehension task in the case of reading or listening. If possible, a record of this activity should be kept to enable a smooth evaluation process once self-directed learning has been initiated.

Setting goals. When learners are able to analyse their own situation and current skill level, they are then able to set priorities and decide on specific goals for self-directed learning. Goal setting has been well-documented in existing literature (Dam, 1995; Karlsson et al, 2007; Cotterall \& Murray, 2009) as a pivotal process in planning self-directed learning. Goal setting helps learners focus their study and break it down into manageable chunks. Learners may have one or two overall goals, but may also choose to set themselves more manageable weekly goals which will help them achieve their more general goals. This can have benefits for motivation, as by making noticeable progress towards a specific goal, learners are more likely to want to continue studying.

Choosing resources. Once learners have analysed their needs and set goals, they must also choose appropriate learning resources. Such resources may be one of two kinds: resources designed for language learning (textbooks, dictionaries, internet sites) or examples of authentic language use (newspapers, radio or TV programmes, podcasts, movies, proficient speakers of the language). In the case of the latter resource type, learners must also decide how they are going to use the chosen resources in a way that will help them achieve their goals. For this, it may be necessary for the teacher to model and have students experiment with certain learning strategies in class. It is important, however, that learners do not lose sight of their goals during this process; sometimes enthusiasm for a newly-found resource or strategy can throw learners off their goal focus.

Making a plan. Once the "what" and the "how" of the self-directed learning have been decided upon, it is useful for learners to make some kind of formal record of their plans. This could take the form of a simple record of goals set, a more detailed plan in which weekly goals, materials, and study activities are laid out, or even a learning contract signed by both the learner and teacher stating that the learner will engage in a certain kind of study for a set time each week or month. Examples of a basic learning plan and a learning contract can be found in Appendices B and C.

\section{Implementing}

After completing a thorough planning process, learners are then ready to start implementing their plan. As Dickinson's (1987) definition suggests, self-directed learners may differ in the degree to which the implementation of their learning activities, as decided through the planning process, is regarded as autonomous. In many situations, learners may opt for a teacher-based form of instruction over more autonomous learning, in which they decide on 
their own materials and design their own study activities. In cases where learners do opt to work predominantly on their own or without specific teacher guidance, it is useful for a clear record of study to be kept. This is for two reasons. By keeping a record of the work they are doing, learners will build up a kind of portfolio that can give them a degree of satisfaction with the work they are doing and motivate them to continue. At the same time, this record can also aid with monitoring and evaluating their learning as they progress through their plan.

A learning record can be kept in a number of ways; learners should be encouraged to choose a method which suits their own preferences and the study they are doing. Some may choose a simple log of what has been studied and when, with titles of worksheets or chapters recorded, along with any test scores they may have. Others may prefer more detailed reflective diary entries. Examples of these kinds of recordkeeping can be found in Appendices D and E. Visual devices, such as graphs or charts of progress made in comprehension tasks or learners' level of satisfaction with their performance, may also be used (Cotterall \& Murray, 2009).

\section{Monitoring}

Developing good monitoring skills involves encouraging both learners' self-awareness and their awareness of the language they are learning. Keeping detailed records of learning, as mentioned above, is vital to this process. In addition to the types of record-keeping introduced, Richards and Lockhart (1996) suggest several ways for teachers to monitor and reflect on their performance. Some of these methods, such as task observations or recordings, may also be suitable for students focusing on their own learning processes. Effective monitoring is the key to good self-directed learning and ensures the recursive nature of the cycle. Learners who fail to monitor their work may lose focus and waste time on study which does not sufficiently address the needs and goals they previously identified. Two types of monitoring can be effective in selfdirected language study: mid-task monitoring and study balance monitoring.

Mid-task monitoring. Learners should be encouraged to examine their study activity mid-task and ask themselves whether the resource or activity they have chosen is actually addressing their goal areas, and if necessary, change their study. For example, a resource chosen in the belief that it will help with academic listening may in fact prove to be more business-oriented. However, learners may be reluctant to give up halfway through a task, even if it is not as beneficial as they believe. Through successful monitoring, students will be able to focus clearly on their goals and avoid spending time on unhelpful activities or resources.

Study-balance monitoring. As any teacher versed in communicative methodology knows, learning a language requires more than just learning about the language. To be successful, students also need to have opportunities to use the language in context, and to review vocabulary and grammar learned, if they are to remember it for future use. Far too often, however, these important stages in the learning process are neglected in favour of pure study. By encouraging students to monitor their study balance, for example by working out what percentage of their weekly work has been Study, Use or Review, teachers can raise awareness of which areas may be lacking.

These forms of monitoring can also be encouraged during classroom tasks. Learners can be asked to consider how the work they are doing in class relates to their own language goals and to identify whether a task is helping them to Study, Use or Review language. In this way, they will be more likely to apply these concepts to their own self-directed study.

Another important aspect of monitoring that teachers can promote in the classroom is language awareness. Research has highlighted the importance of noticing in language learning 
(Robinson, 2006); by paying more attention to their own language input, be it grammar, vocabulary, or wider discourse or genre features, learners can maximize their own opportunities to acquire the language to which they are being exposed. Such activities could be introduced in class as guided discovery grammar or vocabulary activities (Thornbury, 2001).

\section{Evaluating}

The final process which is considered vital for successful self-directed learning is that of evaluating the learning and progress being made. Whereas the monitoring strategies described above primarily examine the learning process, evaluating is often more concerned with the product of that learning process. Evaluation generally takes place once learners have been undertaking self-directed study for a certain period of time, usually at least a month. The main way in which an evaluation can be conducted is through a controlled comparison. This is only possible if learners have investigated and recorded their original skill level in their goal areas during the planning process and have kept a study record of the work they have been doing. For example, having made a recording of a conversation on a certain topic before starting their study, they may now decide to record a similar conversation and compare the two recordings. By comparing their level after engaging in some study with that of their skill before embarking on self-directed learning, learners can determine whether the way they have been learning has had the desired effect on their language proficiency in the focus area. If this turns out not to be the case, they will have to examine their study plan and change it to better fit their goals.

Evaluation can work equally well in the context of classroom activities, with teachers asking learners on completion of a task to evaluate their own performance and to suggest ways in which they could improve in the future. This is particularly useful if learners have the chance to re-do the task. By taking the time to introduce this element to a classroom task, learners can be more confident of their ability to do so during more self-directed learning.

By breaking down self-directed learning skills into this four-step framework, it is hoped that the process of becoming more self-directed will be more manageable for both students who wish to move in this direction and teachers who wish to help students do so. The clear framework can also aid teachers wishing to assess this aspect of their learners' development, as each of the four stages can be clearly evidenced through such aids as learning plans, reflective diaries and learning logs.

\section{Challenges to Successful Self-Directed Learning}

There are a number of issues which may represent a challenge to teachers or institutions aiming to help learners to become more self-directed. Teachers may not feel they have the class time to devote to helping learners organize their learning or may lack confidence in their ability to do so. However, many of the techniques introduced in this paper can be incorporated into existing classroom tasks, and may simply involve including short discussions where students can reflect on and share their ideas and experiences of learning. Learners and teachers themselves may also hold beliefs about language learning and the roles of the student and the teacher which make them resistant to the idea of students assuming more responsibility for their own learning (Little, 1991; Dam, 2008). As previously stated, psychological resistance to autonomy must be addressed, and learners must see the advantages of planning and monitoring their own learning if they are to fully engage in the process. Some learners may choose to reject self-directed learning altogether; however, it is hoped that by introducing certain elements of self-directed learning into classroom activities, those learners who are motivated to learn outside the classroom will do so more effectively. 


\section{Conclusion}

While each of the four phases introduced in this paper are very important for effective selfdirected learning, learners need help if they are to succeed in planning, implementing, monitoring, and evaluating their own learning. By explicitly introducing these aspects of the learning process to learners, and providing opportunities for learners to experiment with them, teachers can play an important role in supporting learners engaging in self-directed learning and developing autonomy as language learners.

\section{Biodata}

Katherine Thornton has an MA in TESOL from the University of Leeds, UK, and works as a Learning Advisor and Lecturer at Kanda University of International Studies in Chiba, Japan. Her research interests include learner autonomy, vocabulary acquisition, and corpus linguistics.

\section{References}

Benson, P. (2001). Teaching and researching autonomy in language learning. Harlow, England: Pearson.

Chamot, A. U., Barnhardt, S., Beard El-Dinary, P., \& Robbins, J. (1999) The learning strategies handbook. New York, NY: Longman.

Cotterall, S., \& Murray, G. (2009). Enhancing metacognitive knowledge: Structure, affordances and self. System 37(1), 34-45. http://dx.doi.org/10.1016/j.system.2008.08.003

Dam, L. (1995). Learner autonomy 3: From theory to classroom practice. Dublin, Ireland: Authentik.

Dam, L. (2008, Spring). In-service teacher education for learner autonomy. Independence (IATEFL Learner Autonomy SIG).

Dickinson, L. (1987). Self-instruction in language learning. Cambridge, England: Cambridge University Press.

Dickinson, L. (1992). Learner autonomy 2: Learner training for language learning. Dublin, Ireland: Authentik.

Griffiths, C. (2008). Lessons from good language learners. Cambridge, England: Cambridge University Press.

Holec, H. (1981). Autonomy and foreign language learning. Oxford, England: Pergamon.

Karlsson, L., Kjisik, F., \& Nordlund, J. (2007). Language counselling: A critical and integral component in promoting an autonomous community of learning. System 35(1), 46-65. http://dx.doi.org/10.1016/j.system.2006.10.006

Little, D. (1991). Learner autonomy 1: Definitions, issues and problems. Dublin, Ireland: Authentik.

McDonough, S. (1999). A hierarchy of strategies? In S. Cotterall \& D. Crabbe (Eds.), Learner autonomy in language learning: Defining the field and effecting change (pp. 51-60). Frankfurt, Germany: Peter Lang.

Munby, J. (1978). Communicative syllabus design. Cambridge, England: Cambridge University Press.

Nunan, D. (1997). Designing and adapting materials to encourage learner autonomy. In P. Benson \& P. Voller (Eds.), Autonomy and independence in language learning (pp. 192203). Harlow, England: Longman.

O'Malley, J. M., \& Chamot, A. U. (1990). Learning strategies in second language acquisition. Cambridge, England: Cambridge University Press.

Oxford, R. (1990). Language learning strategies: What every teacher should know. Boston, MA: Heinle and Heinle.

Richards, J. C., \& Lockhart, C. (1996). Reflective teaching in second language classrooms. Cambridge, England: Cambridge University Press. 
Robinson, P. (2006). Attention, memory, and the "noticing" hypothesis. Language Learning, 45(2), 283-331. http://dx.doi.org/10.1111/j.1467-1770.1995.tb00441.x

Rubin, J., \& Thompson, I. (1994). How to be a more successful language learner. Boston, MA: Heinle and Heinle.

Thornbury, S. (2001). Uncovering grammar. London, England: Macmillan Heinemann. 


\section{Appendix A}

\section{Example of a Needs Analysis Questionnaire}

\section{Study Analysis}

Wants, Interests, Needs (WIN)

1. What are your English Wants,

Interests,

Needs?

2. What kind of English do you need for these situations? (e.g., spoken/written, formal/informal, technical vocabulary, )

\section{Goal Setting}

Look at the kinds of English you've identified above (2). Which of these are the most important for you to improve? (Think about your own strong /weak areas, how important each aspect is, how much work you think you need to do to improve.)

3. Rank your most important ideas in order of priority:

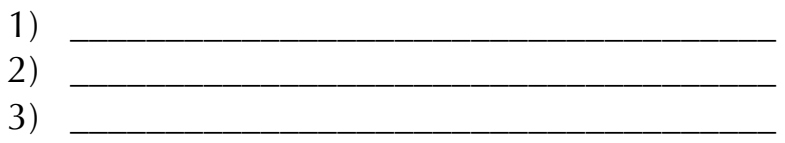

These are your language goals. Now SMARTEN them up - make sure they are:

Specific

Measurable

Attainable

Realistic

Timely

\section{Choosing Learning Materials}

4. How do you think you learn best? Circle all that apply to you.
finding rules
reading
learning rules repeating writing things down testing yourself speaking
translating role-play/practicing doing grammar exercises listening/watching (TV/other people) alone/with others

Mind your surroundings! Think about what English there is around you. (e.g., tourist brochures, newspapers \& magazines, satellite TV, DVDs, novels, radio programmes, people!)

What English study resources do you have access to? Textbooks, dictionaries, Internet, teachers.

How could you use these to help with your GOALS? Think about how you like to study. 
5. Choose 1 or 2 of these resources.

Material 1:

Material 2:

\section{Planning Your Time}

6. How long do you need to reach your goals?

years/months/weeks

7. How long can you REALISTICALLY spend on studying each week? hours

\section{Planning your weekly study:}

Each week, ask yourself the following question:

What are you going to study this week? How?

Remember, good study should have a balance of Study

Use

Review

Before you start, check your current level for each of your goal areas. This will help you to see if you're improving over time. How can you find out? (e.g., word test, recording your speaking, writing sample, reading speed test)

\section{Appendix B}

Example of a Basic Learning Plan

Goal:

Focus area(s):

Resource(s):

Now describe how you will use this resource for these goals. Include STUDY, USE or REVIEW. Remember you can change the order of SUR, and repeat one or more of the areas if necessary.

\begin{tabular}{|l|l|}
\hline Study/Use/Review & Time: \\
\hline Study/Use/Review & Time: \\
\hline Study/Use/Review & \\
& \\
& \\
\hline
\end{tabular}




\section{Appendix C \\ Example of a Learning Contract}

's Learning Contract with Mr. /Ms.

My English goals:

How I will study:

I,__name)

will spend

hours/minutes on these activities each

week/month.

I will submit a weekly/monthly record of my work.

I will do my best to fulfill my obligations as presented in this contract.

Signed (student):

Date:

Signed (teacher):

Date:

\section{Appendix D}

Example of a Reflective Diary

\section{Week One}

1. Describe your learning goals for this week:

2. What materials did you use? Give details (title, URL etc.)

3. How did you study? (Give step-by-step details of what you did.)

4. Post-study reflection. What was successful about your study this week? What will you change in future? Give reasons for your choices. 


\section{Appendix E \\ Example of a Learning Log}

Learning Log

Keep a record of all the independent study you do using this log sheet. Each time, please explain what you did and evaluate your activity.

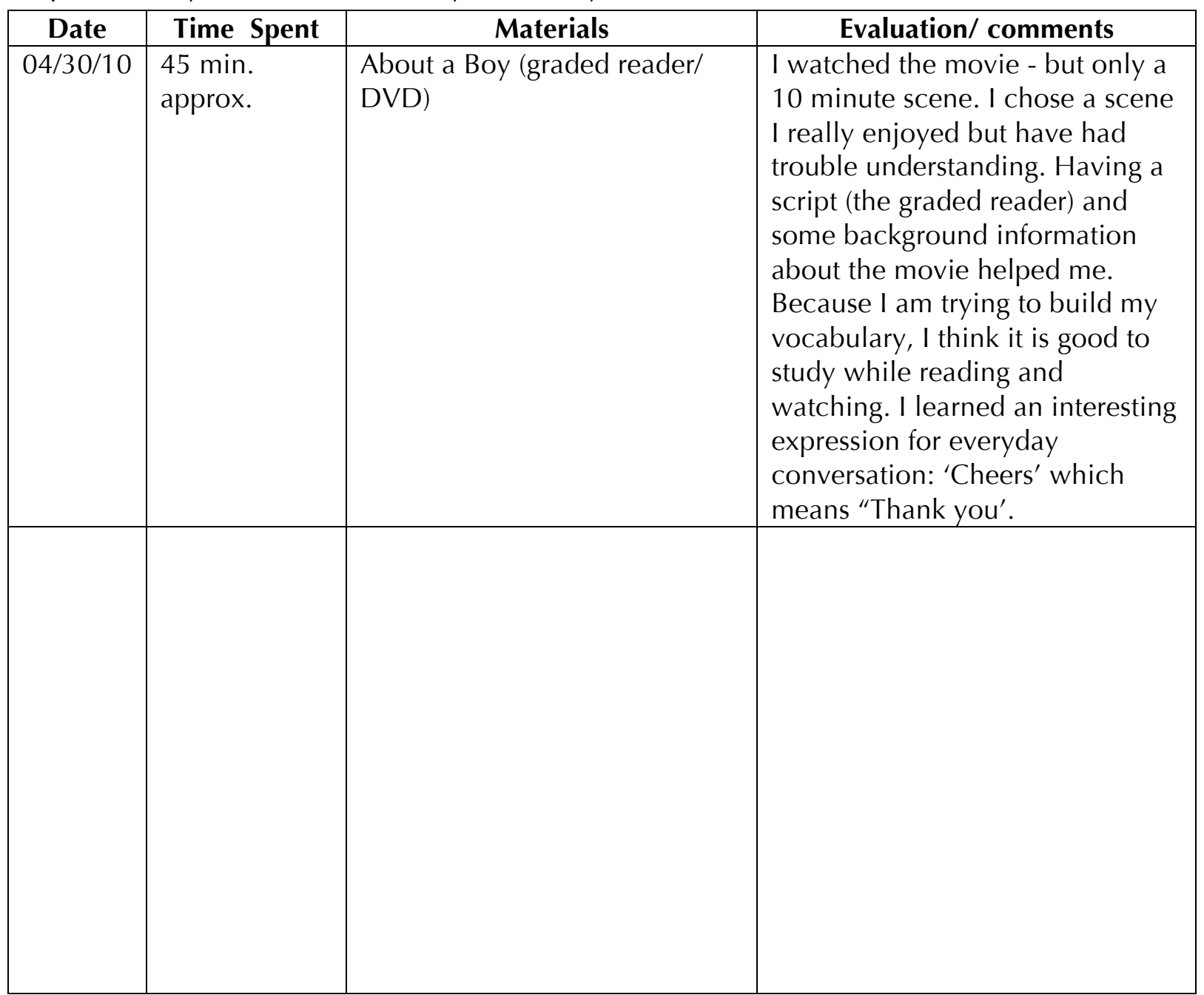

